\title{
Avaliação do escore de condição corporal de machos adultos de cachorros-do-mato (Cerdocyon thous) sob cuidados humanos
}

\author{
HIPPÓLITO, Alícia Giolo1; TESTA, Carolyne Assis Eigenheer Pinke ${ }^{1}$; FERRO, Barbara Sardela ${ }^{2}$ \\ OLIVEIRA, Elton Luís Ritir2; OKAMOTO, Priscylla Tatiana Chalfun Guimarães ${ }^{3}$; MELCHERT, \\ Alessandra ${ }^{3}$

\footnotetext{
1 Doutorandos do Programa de Pós-Graduação de Animais Selvagens - UNESP, Botucatu.

${ }^{2}$ Mestrando do Programa de Pós-Graduação de Animais Selvagens - UNESP, Botucatu.

3Docente da UNESP, Botucatu.

Email: aliciamedvet@gmail.com
}

RESUMO: Os cachorros-do-mato (Cerdocyon thous) são canídeos silvestres adaptados ao ambiente antropizado, atingindo o sucesso reprodutivo nesse novo habitat. Fator primordial para não constar na lista de ameaçados de extinção, como o lobo-guará (Chrysocyon brachyurus) e o cachorro-vinagre (Speothos venaticus). A complexidade do diagnóstico de doenças metabólicas em animais selvagens ainda é um desafio, tanto em vista a grande quantidade de estudos e a evolução da medicina de cães e gatos. Em cativeiro, os animais selvagens estão mais propícios a desenvolver obesidade, por isso, medidas de padrão da espécie fundamentados na conformação e biometria do indivíduo são necessários para se obter maior controle, não se baseando em dados subjetivos que podem diferir de acordo com o profissional. O método mais fidedigno para avaliação da condição de escore corporal dos cachorros-do-mato ( $C$. thous) desse estudo foi o método aplicado em gatos domésticos, no qual é necessário a medida da caixa torácica e o comprimento do meio da patela para a ponta dorsal do calcâneo.

Palavras-chave: canídeos silvestres; índice de massa corporal; obesidade, selvagens; sobrepeso.

\section{INTRODUÇÃO}

O cachorro-do-mato é uma espécie de canídeo silvestre, onívoro, com peso médio entre 4,5 a $8,5 \mathrm{~kg}$. A espécie está adaptada ao ambiente antropizado, atingindo 0 sucesso reprodutivo nesse novo ambiente. Fator primordial para não constar na lista de ameaçados de extinção, como o loboguará (Chrysocyon brachyurus) e o cachorro-vinagre (Speothos venaticus). Quando os canídeos estão em ambientes antropizados e em cativeiro, podem desenvolver desordens metabólicas, que podem culminar em patologias articulares, renais e cardíacas (JORGE; JORGE, 2014). Aumento de peso em animais selvagens pode propiciar síndrome metabólica e doenças cardíacas (KIL; SWANSON, 2010), assim como a desnutrição também é um sério problema, afetando diretamente o sistema imune e estrutura corporal. A obesidade é uma desordem nutricional complexa e multifatorial, e exige manejo adequado (LINDER; MULLER, 2014). As causas incluem maior disponibilidade de alimento, baixo nível de atividades e fatores predisponentes genéticos (RANDIN et al., 2009). A técnica ideal para estimar o escore corporal deve ser seguro, rápido, custo baixo, confiável e de execução (ELLIOT, 2006).

Desta forma, o objetivo desse estudo é utilizar índices de avaliação de escore corporal de cães domésticos em 
cachorro-do-mato (C. thous) para avaliar se os valores numéricos obtidos são representativos do escore observado na espécie, melhorando assim a detecção da obesidade nestes animais.

\section{MATERIAL E MÉTODOS}

Foram utilizados três cachorrosdo-mato (C. thous), provenientes do Centro de Medicina e Pesquisa de Animais Selvagens (CEMPAS) da Faculdade de Medicina Veterinária e Zootecnia - FMVZ - UNESP, Botucatu. Os dados biométricos foram coletados com os animais anestesiados para procedimentos rotineiros do centro. Os animais avaliados eram hígidos, machos, adultos e exibiam bom escore corporal, classificados no escore 5 do método Laflamme (1997). A biometria foi mensurada com auxílio de uma fita métrica e o peso do animal foi aferido em uma balança de precisão, da marca Toledo®. Foram comparados três métodos de avaliação de escore corporal, sendo eles: LAFLAMME, (1997), por ser o método mais utilizado em cães domésticos, MULLER et al. (2008) e BURKHOLDER; TOLL (2000), aplicados em cães e um método utilizado em gatos domésticos (HAWTHORNE; BUTTERWICK, 2000). O método LAFLAMME (1997) indica o escore de condição corporal em uma escala de 1 a 9 pontos. O escore muito magro é estabelecido pelos escores 1, 2 e 3 , sendo o 1 caquético, presença de reentrância abdominal extremamente acentuada e 03 com cobertura de gordura mínima, mas vértebras lombares e cintura ainda evidentes. Escores 4 e 5 são ideais, sendo o 4 sem bolsa de gordura abdominal, discreta reeentrância abdominal, e o 5 com deposição de gordura, mas não excessiva, e abdome retraído quando visto de lado. Os escores 6 a 9 são para animais acima do peso, sendo $9 \mathrm{com}$ costelas impossíveis de palpar devido a uma grossa cobertura adiposa, além de deposição de gordura em face, membros e abdome e ausência de cintura. MULLER et al. (2008) desenvolveram o modelo de índice de massa corpórea canina, no qual o resultado da equação aritmética da massa em quilogramas dividida pelo quadrado da estatura em metros. A estatura é a medida entre a articulação atlanto-occipital passando sob a base da cauda, última vértebra sacral, e descendo até a região do solo, imediatamente atrás dos membros pélvicos. Os resultados da equação aritmética abaixo de 11,7 proporciona a classificação de indivíduos abaixo do peso. Caninos com o resultado entre 11,8 a 15, marcados como ideal; é considerado acima do peso o intervalo de 15,1 a 18,6 e obeso a partir de 18,7. $O$ autor refere boa margem de segurança, sendo possível transformar esse índice acrescido de $20 \%$ para raças grandes e diminuição de $10 \%$ para raças em miniaturas. BURKHOLDER; TOLL (2000), com as medidas biométricas estabeleceram a percentagem de gordura corporal, por meio da seguinte equação, destinada cães machos: - 1,4 (MP) + 0,77 (PA) + 4 , onde $\mathrm{MP}$, comprimento entre a tuberosidade do calcâneo e o ligamento patelar médio e perímetro abdominal (PA) ponto médio entre a asa do íleo e a última vértebra torácica; aferidos em centímetros. Animais que obtém a percentagem de 15 a $25 \%$ estão no escore ideal. De 25-30\%, o animal apresenta sobrepeso e acima de $30 \%$ são considerados obesos. HAWTHORNE; BUTTERWICK (2000) calcularam o conteúdo de gordura corporal de gatos domésticos a partir da equação: [(CT/0,7062) - RC/0,9156] $\mathrm{RC}$, onde CT é a dada pela circunferência da caixa torácica e $\mathrm{RC}$, o comprimento do meio da patela para a ponta dorsal do calcâneo. Considerado escore corporal ideal entre 15 a $30 \%$. 


\section{RESULTADOS E DISCUSSÃO}

Os resultados da biometria dos indivíduos estão na Tabela 1.

\begin{tabular}{cccccc}
\multicolumn{6}{c}{ Tabela 1. Biometria de cachorro-do-mato (Cerdocyon thous), machos adultos } \\
\hline Animal & Peso $(\mathrm{kg})$ & $\begin{array}{c}\text { Comprimento } \\
\text { total }(\mathrm{m})\end{array}$ & $\begin{array}{c}\text { Perímetro } \\
\text { Abdome }(\mathrm{cm})\end{array}$ & $\begin{array}{c}\text { Perímetro } \\
\text { Tórax }(\mathrm{cm})\end{array}$ & $\begin{array}{c}\text { Patela - } \\
\text { Calcâneo }(\mathrm{cm})\end{array}$ \\
\hline 1 & 7,35 & 0,93 & 35 & 45 & 17 \\
2 & 7,76 & 0,88 & 42 & 45 & 16,5 \\
3 & 6,50 & 0,85 & 34 & 43 & 16 \\
\hline
\end{tabular}

Os resultados das fórmulas de acordo com os autores estão na Tabela 2.

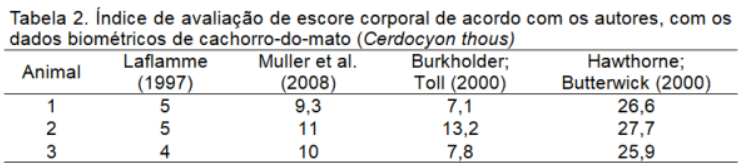

Os dois métodos de avaliação de escore corporal de cachorro doméstico, MULLER et al. (2008) e BURKHOLDER; TOLL (2000) não refletiram o verdadeiro escore corporal referido por LAFLAMME (1997). Esses métodos apontam que os animais estavam abaixo do peso. O escore de condição corporal referido por HAWTHORNE; BUTTERWICK (2000) utilizados em gatos domésticos demonstrou que os animais no estudo estavam em bom escore corporal, escore 5 do método Laflamme (1997). O grande benefício da avaliação da condição corporal dos animais através de uma fórmula é remover possíveis subjeções de avaliação aplicada pelos profissionais e a mensuração da quantidade de massa que o paciente deve emagrecer ou engordar (CARVALHO, 2015). A medicina veterinária de pequenos animais é a base para 0 entendimento para a medicina de animais selvagens, entretanto, a extrapolação de animais domésticos deve ser realizada com cuidado, pois como foi visto nesse caso, a aplicação do índice de condição corporal de um cachorro-doméstico para a espécie cachorro-do-mato ( $C$. thous) não foi válido. $O$ índice mais indicado foi
- método utilizado para gatos domésticos. Apesar de esses animais estarem em bom escore corporal, escore 5 do método Laflamme (1997), existe uma grande tendência de animais em cativeiro apresentarem sobrepeso, pois nos recintos em que esses indivíduos permaneceram não havia enriquecimento ambiental, fato que pode propiciar a falta de exercícios e consequentemente a obesidade (JERICÓ et al., 2009).

\section{CONCLUSÃO}

O método mais fidedigno para avaliação da condição de escore corporal desses cachorros-do-mato (Cerdocyon thous) foi o método aplicado em gatos domésticos.

\section{AGRADECIMENTOS}

Os autores agradecem ao Centro de Medicina e Pesquisa de Animais Selvagens - CEMPAS, pelos dados dos animais.

\section{REFERÊNCIAS}

BURKHOLDER, W. J.; TOLL, P. W. Obesidad. In: Hand, M. S. et al. (Ed.). Nutrición clínica en pequeños animales: small animal clinical nutrition. 4 th ed. Buenos Aires: Inter-Médica S.A.I.C.I., 2000. p. $475-508$

CARVALHO, L. A. R.; Estudo comparativo entre quatro métodos de aferição de condição corporal em cães; Dissertação de mestrado; Universidade Federal de Lavras; 68p.; 2015.

ELLIOT, D. A.; Técnicas para avaliar a composição corporal em cães e gatos. Waltham Focus, v. 16, n.1, p. 16-20, 2006.

HAWTHORNE, A.J.; BUTTERWICK, R.F. Predicting the body composition of cats: development of a zoometric 
measurement for estimation of percentage body fat in cats. J. Vet Intern Med, v.14, n.3, p.349-365, 2000.

JERICÓ, M. M.; ALBINATI, J. M.; FUSCO, F. B.; Estudo sobre os hábitos alimentares e as atividades físicas de cães obesos da cidade de São Paulo e seus reflexos no balanço metabólico. Rev Clín Vet, São Paulo, v. 14; 2009.

JORGE, R.S.P.; JORGE, M.L.S.P.; Carnivora - Canidae (Cachorro-domato, Cachorro vinagre, Lobo-guará e Raposa-do-campo). In: Cubas, Z.S.; Silva, J.C.R., Catão-Dias, J.L.; Tratado de Animais Selvagens: medicina veterinária. 2014.

LAFLAMME, D. P.; Development and validation of a body condition score system for dogs: a clinical tool. Can Pract, Santa Barbara, v. 22, 1997.

LINDER, D.; MUELLER, M. Pet Obesity Management. Vet Clin North Am: Small Animal Practice, v. 44, n. 4, p.789-806, 2014.

MÜLLER, D. C. M.; SCHOSSLER, J. E.; PINHEIRO, M. Adaptação do índice de massa corporal humano para cães. Ciência Rural, Santa Maria, v. 38, n. 4, p. 1038-1043, jul. 2008.

RANDIN, M. J.; SHARKEY, L. C.; HOLYCROSS, B. J.. Adipokines: a review of biological and analytical principles and an update in dogs, cats, and horses. Vet Clin Pathol, v. 38, n. 2, p.136-156, 2009.

\begin{abstract}
Agradecemos ao apoio da Fundação Araucária e da Coordenação de Aperfeiçoamento de Pessoal de Nível Superior - CAPES na realização do $3^{\circ}$ Workshop de Nutrição de Animais Selvagens.
\end{abstract}

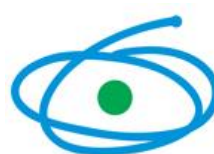

CAPES

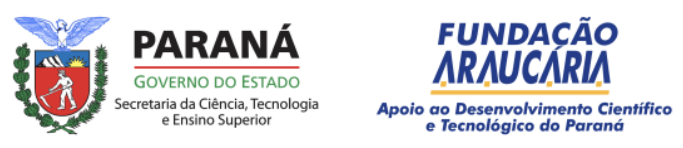

